\title{
Price and Volume Effects Associated with Changes in the Danish Blue-Chip Index: The KFX Index
}

\author{
Ken L. Bechmann \\ Copenhagen Business School, Denmark
}

This paper considers the effects of changes in the composition of the Danish blue-chip KFX index for the period of 1989-2001. Consistent with the selection criterion used for the index, there is no evidence for a stock price effect at the announcement of a change in the index. However, deleted stocks experience an abnormal return averaging $-13 \%$ in a six-month period before the deletion and a decrease in trading volume and efficiency of stock prices following the deletion. For added stocks, the average abnormal return is $8 \%$ and there is no significant change in trading volume or efficiency. These long-run effects are best explained by the imperfect substitutes hypothesis or the information costs/liquidity hypothesis, suggesting that stocks in the KFX Index are exposed to a higher demand or more attention and a lower cost of trading than stocks outside the index. However, the results do not rule out the possibility that part of the stock price effect is due to the selection criterion used for the KFX Index. All in all, this paper documents that the selection criterion for and the size of an index as well as the size of the related stock market are relevant when explaining the stock market effects of index revisions (JEL: G11, G14).

Key words: index composition; selection criterion; price and liquidity effects.

\section{Introduction}

The effects on prices and trading volume when a stock is added to or deleted from stock market indices have been widely examined for the U.S. stock market. The great interest is due to the fact that such effects

\footnotetext{
* The author acknowledges helpful comments from Rolf Allen, Elroy Dimson, Lawrence Kryzanowski, Beni Lauterbach, Randall Morck, Michael Møller, Henrik Nordestgaard, Claus Parum, Torben Voetmann, and in particular two anonymous referees. The author would also like to thank the participants in the International Stock Market Seminar, the finance seminar at Copenhagen Business School, the Centre for Analytical Finance seminar, the EFMA, the FMA-European, and the MFS 2002 conferences.
}

(Multinational Finance Journal, 2004, vol. 8, no. 1 \& 2, pp. 3-34)

(C) Multinational Finance Society, a nonprofit corporation. All rights reserved. DOI: $10.17578 / 8-1 / 2-1$ 
provide important insight into the functioning of stock markets and the behavior of stock market participants, including fund managers. In addition, some of the findings indicate inefficiencies in the stock market. The existing literature provides mixed results on the magnitude and duration of the effects and gives a variety of different explanations for the findings.

This paper examines the effects on stocks added to and deleted from the Danish blue-chip index, the KFX Index, for the period of 1989-2001. The inspiration for this paper comes partly from an incident that occurred on May 29, 2000, when a Danish financial news wire announced that the stock of software firm Damgaard A/S would be added to the KFX Index due to an ongoing delisting of a current KFX stock. The announcement was released shortly after the stock exchange opened and stated that the news was based on information from the Copenhagen Stock Exchange. The announcement caused an immediate stock price increase from DKK 360 to DKK 393, with trades made at prices as high as DKK 420, which corresponds to an announcement effect of at least $9 \%$. However, a few hours later, the stock exchange announced that the stock of Damgaard A/S would not be added to the KFX Index, at which point the stock price immediately dropped back to DKK 360 where it stayed for the rest of the day. Therefore, based on this incident, the stock price effect for Damgaard A/S of being added to the KFX Index is apparently around $9 \%$.

While it is relevant to formally test whether such a stock price effect holds more generally, there are two additional reasons why it is interesting to examine changes in the KFX Index. First, there is the specific selection criterion used for the Danish KFX Index. For many other stock market indices, most notably the S\&P 500, the selection criterion used is vague and not based on specified publicly available information. Furthermore, deletions from many stock market indices are primarily due to corporate events such as mergers, acquisitions, and spin-offs, leaving only relatively few clean deletions.

In contrast to such indices, the composition of the KFX Index is based on a publicly announced selection criterion using information accessible for all market participants. As described later, the KFX selection criterion is such that the addition of a stock to the KFX Index does not provide any new fundamental information about that stock to the stock market. Therefore, with regard to the KFX Index (and a few other indices with similar selection procedures), it is possible to examine some of the explanations for an index effect completely separate from an information signaling explanation. Similarly, the KFX 
selection criterion also implies that the number of clean additions and clean deletions will be approximately the same, making it possible to rigorously examine both the evidence related to deletions and to make a more credible comparison between the two types of revisions. Finally, because of the strictly enforced selection criterion, some stocks are added to and deleted from the KFX Index several times. Hence, the KFX Index provides quite a unique opportunity to examine whether it matters for the index effect if it is the first time a stock is added to or deleted from the index or not.

The second reason why the KFX Index is interesting concerns the period between the date at which the composition of a new index is determined and announced (the announcement date) and the date when the new index comes into effect (the effective date). This period is normally about one month, making it possible to consider the effects on stock prices and trading volume around the two dates separately. For most other stock market indices, this time period is normally much shorter, varying from zero days to approximately one week, preventing such a distinct consideration.

The remaining part of this paper is organized as follows. Section II provides some details on the selection criterion used for the KFX Index as well as the competing explanations for an index effect. Section III describes the data-set and the methodology used. The results are presented in section IV, while section V discusses the implications of the results and offers some conclusions.

\section{The KFX Index and Explanations for an Index Effect}

One important aspect of the KFX Index is the selection criterion used to determine the composition of the index. As a result, this section starts with a more detailed description of the KFX Index and its selection procedure. Section II.B gives an overview of the explanations for an index effect and the related literature. Finally, section II.C discusses competing explanations with regard to revisions of the KFX Index.

\section{A. The KFX Index and the Selection Criterion}

The KFX Index was introduced in 1989 to both represent the development in stock prices of major Danish blue-chip companies and to be used as an underlying index in connection with the establishment of an option and futures market on the Copenhagen Stock Exchange. 
The KFX Index is the most important Danish stock index, currently constituting $67 \%$ of the total market value and accounting for $80 \%$ of the total market turnover. More or less the same publicly announced selection criterion has been used to determine the index since its introduction and up to June $1,2001{ }^{1}$

According to this selection criterion, the KFX Index is selected through a two-step selection procedure on each revision date. First, the exchange selects the basis portfolio, which consists of the 25 most traded stocks determined in the following way. For each trading day in the reference period (typically the preceding six months), a list is made of the 25 most traded stocks. Then, the 25 stocks that featured most frequently on the daily top- 25 lists during the reference period are selected for the basis portfolio. Next, these stocks are ranked according to their total market value on the trading day preceding the revision date. The 20 stocks with the highest market value are then selected as the new KFX Index, which comes into effect approximately four weeks after the selection and announcement hereof. ${ }^{2}$

The new selection criterion that became effective on June 1, 2001 considers only the trading volume of the stocks. The 20 stocks in the index are now selected solely based on the market value of stocks traded during the reference period. ${ }^{3}$

\section{B. Explanations for an Index Effect and Related Literature}

Ever since Shleifer (1986) and Harris and Gurel (1986) first found a price effect for revisions of the S\&P 500 index, many papers have

1. In connection with the revision of the index in November 2000, several firms were accused of trading on the stock market in an attempt to be included in the KFX Index. Following this incident, the Copenhagen Stock Exchange decided to change the selection criterion and the reference period used for the revision.

2. The only changes in this procedure during the period from 1989 to June 1, 2001 have been with respect to the frequency of the revisions, the number of stocks in the index, and the length of the time period between the announcement date and the effective date. The frequency of the revisions has varied from being every three months to just once a year. Until 1992 the number of stocks included in the basis portfolio was 40 instead of 25 , while the KFX Index consisted of 25 stocks instead of 20. The length of the time period between the announcement date and the effective date has varied from three to six weeks.

3. There is an additional requirement that the stock has to have been on the daily top- 25 lists described above at least $40 \%$ of the days in the reference period. However, this additional requirement has not been an issue in any of the revisions until now. A more detailed description of the KFX Index can be found in "Guidelines for Calculation of the KFX Index" published by the Copenhagen Stock Exchange (http://www.cse.dk). 
considered index revisions. Several explanations have also been suggested for the stock market effects. In the following, five different explanations are discussed briefly and the related literature is reviewed.

The first hypothesis is the information signaling or the certification hypothesis, according to which being added to (deleted from) an index is taken as good (bad) news regarding the stock's future prospects. One case in which changes in an index can reveal new fundamental information is when an index committee determines the composition of the index. In this case, the addition of a firm's stock can certify the committee's opinion on the firm's longevity and/or leadership in a specific industry. ${ }^{4}$ Jain (1987) finds evidence for a permanent stock price effect for S\&P 500 revisions and suggests that the effect is due to new information revealed by the announcements. Similarly, Dhillon and Johnson (1991) provide some evidence in favor of the information signaling hypothesis.

The addition of a stock to an index can lead to either an increase in the demand for the stock or the trading of the stock, while its deletion may have the opposite effect. ${ }^{5}$ Depending on whether such a change in demand for the stock or trading of the stock has a temporary or more permanent effect, the price pressure hypothesis or the imperfect substitutes (downward-sloping demand curves) hypothesis applies.

In the case of price pressure, the change in demand (or supply) is only temporary around the announcement or the effective date when investors are re-balancing their portfolios. Such short-term order imbalances can cause a temporary stock price effect.

The stock price effect is of a more permanent nature if different stocks are not close substitutes, whereby stock prices have to increase in order to eliminate an excess demand for a stock caused by the addition of the stock to an index. This leads to the imperfect substitutes hypothesis, according to which a permanent stock price effect is

4. This argument is perhaps especially relevant for U.S. stock market indices such as the $\mathrm{S} \& \mathrm{P} 500$, whose composition is decided by an index committee using loose selection criteria. An example of such criteria is that firms in the S\&P 500 must be leading companies which reflect the U.S. stock market.

5. There are at least four possible reasons for this. First, there are different types of funds (so-called index funds or index trackers) that primarily invest in stocks in certain indices; e.g., Pruitt and Wei (1989). Second, many stock indices are used as benchmarks for active portfolio managers, which can increase their incentives to invest in the stocks in the index. A third reason is that foreign investors invest primarily in stocks from the major stock indices. Finally, futures and options are often traded on a stock market index. Hedging to minimize the risk involved with such instruments also increases trading in the stocks in the index. 
expected as long as the stock is in the index. The expected effect on trading volume is less clear and can be either short-term or permanent, depending on the trading behavior of the investors causing the change in demand. ${ }^{6}$

Regarding additions to the S\&P 500, Harris and Gurel (1986) find that stock prices fully revert to their pre-event levels within two weeks and that trading volume increases around the announcement. These findings provide evidence for the price pressure explanation. Similarly, Elliott and Warr (2003) also find evidence for price pressure, but only at the effective date. In contrast to these results, Shleifer (1986) finds a permanent stock price increase for additions to the S\&P 500 index and uses the imperfect substitutes hypothesis to explain this. The evidence in Wurgler and Zhuravskaya (2002) also supports the imperfect substitutes hypothesis.

The fourth hypothesis, the information costs/liquidity hypothesis, states that an addition to an index increases the information available and lowers the general costs of trading the stock because stocks in the main indices generally attract more attention. An increase in the information available coupled with a potential increase in trading volume can lower the bid-ask spread and thus lower overall transactions costs. Therefore, for stocks added to an index a permanent positive stock price effect and an increase in the liquidity of the stock are expected.

Dhillon and Johnson (1991) provide a variety of evidence which also supports the information costs/liquidity explanation. Chen, Noronha, and Singal (2004) find a positive permanent price effect for additions, but no significant price effect for deletions from the S\&P 500. The explanation for this asymmetry is that investors become more aware of a stock following an addition to the index, but do not become as equally unaware of a stock upon its deletion. Hegde and McDermott (2003) provide evidence that the direct cost of trading increases for deletions and decreases for additions to the S\&P 500. Beneish and Gardner (1995) examine changes in the Dow Jones Industrial Average (DJIA) and find that deletions from the index experience negative abnormal returns while additions have no stock price effect. The explanation suggested is that added firms are usually actively traded prominent

6. For example, the effect is short-term if investors simply follow buy-and-hold strategies. In this case, there will only be an increase in the trading volume around the change in the index when additions are bought and deletions sold. As long as a stock is part of an index, the trading volume is simply normal or perhaps even lower than normal. On the other hand, if investors generally buy and sell stocks that are part of an index, the increase in trading volume is permanent as long as the stock is part of the index. 
firms, whereas deleted firms are often smaller, less actively traded firms. Therefore, according to the information costs/liquidity hypothesis, only the latter of the two groups will experience an effect.

A final and somewhat different explanation for some of the effects is the selection bias or selection criterion hypothesis, which states that the reason for the effects is related to the criterion used to determine the composition of the index. A selection bias can, for instance, be present if only certain stocks - for example stocks with high returns in the period before a revision - are added to the index. We will return to this explanation as applied to the KFX Index in the next subsection.

Several studies have examined indices other than the S\&P 500 and DJIA. ${ }^{7}$ Unfortunately, only a few of these studies provide details on the selection criterion used for the composition of the index under consideration. Similarly, most of these studies also fail to discuss the potential relevance of the selection bias hypothesis for the results. Chung and Kryzanowski (1998), Chan and Howard (2002), and Madhavan (2002) are exemptions which are interesting for at least three reasons. First, the indices examined have revision practices that have some similarities with the one used for the KFX Index. Second, the potential relevance of the selection bias is discussed in these papers. Finally, the evidence found in these papers suggests the existence of price pressure as well as a liquidity effect.

To conclude, the existing literature shows that revisions in general lead to a stock price effect, but that the evidence varies on whether the effect is temporary or permanent. The literature is also inconclusive with respect to the effect on liquidity. Furthermore, there is no universally agreed-upon explanation for these findings. This paper will contribute to the existing literature by doing the first study of the KFX Index. Before looking at the details of the data, however, competing explanations with regard to changes in the KFX Index are discussed.

\section{Explanations with Regard to the KFX Index}

We begin by noting that the "pure" information hypothesis can be ruled

7. Barontini and Rigamonti (2000) examine the MIB30 and MIDEX (Italy), Bildik and Gulay (2001) examine the ISE-30 and ISE-100 (Turkey), Brealey (2000) examines the FTSE (UK), Chan and Howard (2002) examine the AOI (Australia), Chung and Kryzanowski (1998) examine the TSE300 (Canada), Deininger, Kaserer, and Roos (2002) examine the DAX (Germany), Elayan, Li, and Pinfold (2001) examine the NZSE10 and NZSE40 (New Zealand), Liu (2000) examines the Nikkei500 (Japan), and Madhavan (2002) examines the Russell3000 (U.S.). 
out completely as an explanation for any effects. The reason is that the KFX selection criterion implies that it is not possible for the revision to reveal any new fundamental (or private) information to the stock market. ${ }^{8}$

Next, we must remember that the selection criterion for the KFX Index implies that changes in the index will, in general, be anticipated. ${ }^{9}$ In a perfect capital market, this implies that a possible stock price effect from a change in the index is expected in the period before the announcement of the change because an effect should be observed as it becomes more and more likely that the stock in question will either be deleted or added to the KFX Index. Hence, the only possibility for a stock price effect to be found close to the announcement or the effective date is if abnormal trading volume around these dates creates price pressure, and the effect is then expected to be temporary.

This leads to two reasons why it can be difficult to determine the exact size and location of a possible stock price effect. First, the certainty by which a change can be predicted differs from one revision to another, which implies that the stock price effect occurs at different points in time relative to the announcement date. Second, as mentioned, a stock can be deleted or added to the index several times. Therefore, when determining the value of being added to the KFX Index, the stock market may take into account the likelihood that the stock can later be deleted, the likelihood of which may vary from stock to stock.

For the KFX Index, the selection bias hypothesis is perhaps also of some relevance because, even though trading volume is the main impediment, the market value of the stock is also part of the selection criterion. Given this, part of an effect may simply be caused by the fact that stocks selected for the KFX Index are likely to be stocks which have increased in market value. The opposite applies regarding deletions. However, for the KFX Index, the reference period is (at least) six months before the revision of the index. This implies that if the selection bias is the only explanation for an effect, the effect is expected to be distributed evenly over the whole reference period and not only over a relatively short period of time before the revision of the KFX Index. Furthermore, the selection bias hypothesis does not suggest any time pattern in stock price effects nor does it allow for any stock price effect such as that

8. Other studies have examined such information less events in connection with stock market indices. One such event is the change of the index weights or free-float measures for the individual firms currently in an index. See, for example, Kaul, Mehrotra, and Morck (2000).

9. For instance, since 1994, some of the major Danish investment banks have published predictions of the changes in the KFX Index. The announcement of these predictions starts approximately one month before the selection of the new index. 
found in the case of Damgaard A/S mentioned in the introduction.

Finally, there are also arguments as to why we might expect different effects for deletions and additions. According to "market wisdom", and as clearly confirmed by our findings, stocks in the KFX Index are generally more liquid and derive more attention than stocks outside the index. Hence, the selection criterion implies that in order for a new stock to be added to the index, the stock must have quite a high trading volume, which suggests that deletions often will be caused by a decrease in market value. Therefore, added stocks are heavily traded stocks, whereas deleted stocks are often the stocks currently experiencing a decrease in market value, suggesting that the negative effect from a deletion might be more severe than the positive effect following an addition.

This asymmetry in the case of the KFX Index is in contrast to the asymmetry discussed in Chen, Noronha, and Singal (2004) for the S\&P 500. However, there is also a large difference in the size of the two indices and the associated stock markets. The KFX Index consists of only 20 stocks, all issued by large, well-known Danish firms, and hence, what seems to matter the most in connection with the KFX Index is whether or not a stock is in the 'premier league'. ${ }^{10}$ Therefore, another contribution of this paper is to illustrate the importance of taking characteristics of the index and size of the associated stock market into account when examining and explaining an index effect.

All in all, we are left with several competing explanations for an effect in the case of the KFX Index. However, the implications of the selection criterion described above along with results on stock prices and trading volume can help to shed light on these explanations.

\section{Data-set and Methodology}

\section{A. Data-set}

In order to examine the effects of changes in the composition of the KFX Index, all changes since its introduction in 1989 have been determined. Next, all changes related to name changes, mergers, spin-offs or delistings of the stock were removed from this initial set of

10. It is the case for the KFX Index, for example, that KFX stocks are always reported first in all stock lists and on the home page of the Copenhagen Stock Exchange. 


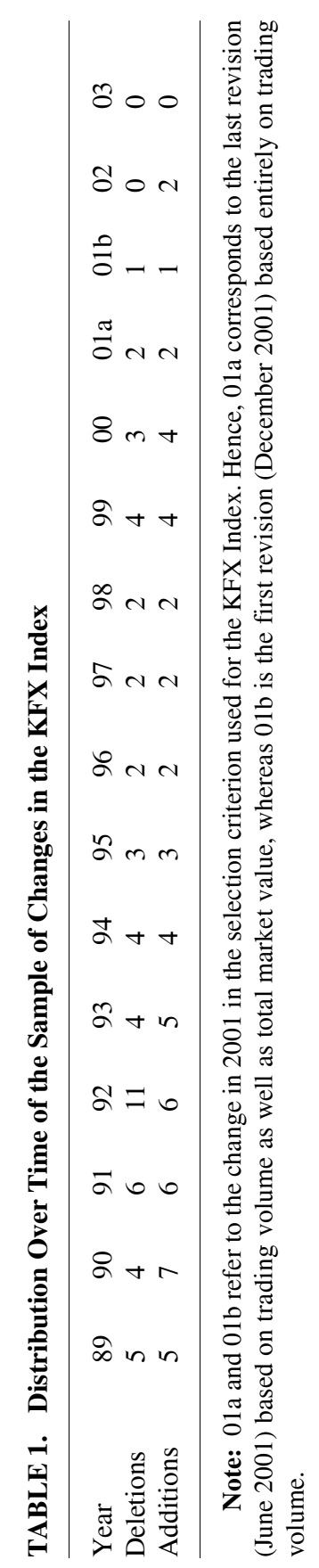


changes. ${ }^{11}$ Furthermore, the latest changes based on the new selection criterion are not considered because there are too few observations to justify a detailed analysis. This leads to a data-set consisting of 52 observations of stocks which were deleted from the KFX Index and 52 observations of stocks which were added. Only a total of 46 different stocks are involved because some of the stocks have been deleted or added to the index several times. ${ }^{12}$ The distribution of the changes over time is seen in table 1 . The table shows that even though there are slightly more changes in the earlier periods where the index was changed every three months, clustering does not seem to be a severe problem. Additional analysis of the data-set also reveals that the distribution of the observations between different industries is quite similar to that of the Copenhagen Stock Exchange. Hence, there does not seem to be any problem with industry clustering.

For each stock, information on prices and trading volume is obtained from Datastream and the Danish stock database, denoted Boersdatabasen. Daily stock returns (continuously compounded) are calculated from the stock prices and adjusted for dividends. The return on the Danish All-Share Index (KAX) is used as market return. ${ }^{13}$ The daily total trading volume on the Copenhagen Stock Exchange was collected manually from the Daily Stock Price Record (Officiel Kursliste) for the Copenhagen Stock Exchange.

\section{B. The Methodology}

There is no standard and agreed-upon methodology for identifying and examining long-run stock price effects. In particular, it has been widely

11. Only a few stocks (four deletions and three additions) were removed from the initial sample, showing that nearly all changes in the index have been due to deletions and additions to the index. This is different from, for example, the S\&P 500, where most deletions are related to mergers, acquisitions, reorganizations or bankruptcies.

12. There are 17 cases where deleted stocks have experienced a previous deletion and 15 cases where added stocks have been added to the index before. In one extreme case, there is a bank that has been added to the KFX Index five times and deleted four times. For the rest of the sample, no other stocks have been added more than two times and only three stocks have been deleted three times.

13. The All-Share Index is a market-value-weighted index for all stocks traded on the Copenhagen Stock Exchange. The All-Share Index is used because the stock price effect of changes in the KFX Index can influence the index itself. However, the returns on the KFX Index and on industry indices have also been used as market return. The results regarding abnormal returns are quite similar to those obtained when using the All-Share Index. 
discussed how adjusted stock returns should be calculated and tested. ${ }^{14}$ In general, the more advanced methodologies rely on identifying either a carefully selected reference sample of stocks or a sample of 'non-event' stocks, unfortunately making them unsuitable for the present study. One main reason for this is data limitations, the size of the Copenhagen Stock Exchange preventing the identification of a sufficient number of 'non-event' stocks for these methodologies to be applicable. Another problem is that, in most cases, 'non-event' stocks for additions will be deletions from the index and visa versa.

Therefore, in order to examine the stock price effects associated with changes in the KFX Index, only the standard event-study methodology remains. ${ }^{15}$ In order to avoid a possible bias caused by a pre-event estimation period, a post-event estimation period is used to estimate the market model. ${ }^{16}$ More precisely, the parameters in the market model are estimated using the period from $E D+120$ to $E D+260$, where $E D$ is the effective date.

Given that the more advanced methodologies are inapplicable, the event study results should be interpreted with some care. However, it is important to stress that the basic results and conclusions are very robust with regard to varying model specifications and implementations of the standard event-study. In particular, the basic results do not change if simple market adjusted returns, wealth relatives, other market indices, or other estimation periods are used as long as the estimation period does not include the six months immediately prior to the change in the index. These findings are consistent with observations made in much of the literature - see, for example, Lynch and Mendenhall (1997) or Chan and Howard (2002) for an overview.

In order to provide further insights into the effects on stock prices, the relation between the return for stock $i$ and the market index is estimated using the market model. Following, for example, the method of Amihud, Mendelson, and Lauterbach (1997), the lagged return on the market is included. This is done in order to examine if a change in the

14. See, for example, Fama (1998) and Lyon, Barber, and Tsai (1999).

15. The standard event-study methodology is described in, for example, Campbell, Lo, and MacKinlay (1997) and Travlos, Trigeorgis, and Vafeas (2001).

16. Given a potential selection bias, deletions (additions) are expected to underperform (overperform) on the market in the period before the change. Hence, using a pre-event estimation period would create a bias in abnormal returns. Edmister, Graham, and Pirie (1994) consider this problem with regard to the effect of changes in the S\&P 500 Index, while Chung and Kryzanowski (1998) do the same for changes in the TSE300 Index. 
KFX Index changes efficiency, for instance, if an addition makes stock returns more synchronous. More precisely, for each stock $i$ and for different time periods relative to the change in the index, the following ordinary least squares regression is run:

$$
R_{i, t}=\alpha_{i}+\beta_{i} R_{m, t}+\beta_{-1, i} R_{m, t-1}+\varepsilon_{i, t}
$$

Here $R_{i, t}$ denotes the return for stock $i$ on day $t$, while $R_{m, t}$ and $R_{m, t-1}$ denotes the return on the market index (the All-Share Index) on date $t$ and $t-1$, respectively. ${ }^{17}$

In order to examine whether being deleted or added to the index leads to a change in the liquidity of a stock, the trading volume is analyzed by calculating the relative volume of each stock as a percentage of the total market volume for each event-day, where both volumes are measured in monetary units. More specifically, for stock $i$ on date $t$, trading volume is measured using the volume ratio, $V R_{i, t}$, defined as:

$$
V R_{i, t}=\frac{V_{i, t}}{V_{m, t}}
$$

where $V_{i, t}$ is trading volume of stock $i$ and $V_{m, t}$ is total trading volume at the Copenhagen Stock Exchange on day $t$ (both in monetary units). ${ }^{18}$

\section{Results}

In this section the effects of changes in the KFX Index are described in three parts. Section IV.A considers the stock price effects around both the announcement and the effective date as well as the stock price effect over a longer time horizon. Section IV.B provides results on the effect on trading volume. Section IV.C makes a cross-sectional examination

17. The KFX Index itself has also been used here as the market index, changing the size of especially the estimated $\beta$ parameter, but not the conclusions.

18. Changes in trading volume have also been examined using several other measures. See Harris and Gurel (1986) and Beneish and Gardner (1995) for descriptions of other volume measures. Chung and Kryzanowski (1998) illustrate the importance of using a market adjusted volume measure such as the one used here, and Jiang and Kryzanowski (1997) discuss different measures of liquidity and examine the relationship between volatility and these measures. 
TABLE 2. Abnormal Returns Around the Announcement and Effective Dates

\begin{tabular}{|c|c|c|c|c|c|}
\hline & & & eletions & & \\
\hline & Event days & $\overline{A R}$ & Median $A R$ & t-test & $\%>0$ \\
\hline & -1 & $-0.09 \%$ & $-0.04 \%$ & -0.54 & $48.0 \%$ \\
\hline$A D$ & 0 & $-0.22 \%$ & $-0.23 \%$ & -1.05 & $44.2 \%$ \\
\hline & +1 & $-0.14 \%$ & $-0.09 \%$ & -0.71 & $46.2 \%$ \\
\hline & -1 & $-0.63 \%$ & $-0.53 \%$ & $-2.66^{* * *}$ & $36.5 \% * *$ \\
\hline$E D$ & 0 & $-0.01 \%$ & $-0.07 \%$ & -0.04 & $48.0 \%$ \\
\hline & +1 & $0.12 \%$ & $0.05 \%$ & 0.46 & $53.8 \%$ \\
\hline & $-1:+1$ & $-0.51 \%$ & $-0.52 \%$ & -1.40 & $42.3 \%$ \\
\hline & & & dditions & & \\
\hline & Event days & $\overline{A R}$ & Median $A R$ & t-test & $\%>0$ \\
\hline & -1 & $0.28 \%$ & $0.03 \%$ & 1.44 & $51.9 \%$ \\
\hline$A D$ & 0 & $0.26 \%$ & $0.17 \%$ & 1.45 & $55.8 \%$ \\
\hline & +1 & $0.65 \%$ & $0.18 \%$ & $2.20 * *$ & $65.4 \% * *$ \\
\hline & -1 & $0.97 \%$ & $0.66 \%$ & $3.58 * * *$ & $69.2 \% * * *$ \\
\hline$E D$ & 0 & $-0.32 \%$ & $-0.25 \%$ & $-1.91 *$ & $32.7 \% * * *$ \\
\hline & +1 & $-0.11 \%$ & $-0.13 \%$ & -0.74 & $44.2 \%$ \\
\hline & $-1:+1$ & $0.54 \%$ & $0.06 \%$ & $1.68^{*}$ & $50.0 \%$ \\
\hline
\end{tabular}

Note: The mean and median abnormal return and the fraction, $\%>0$, of positive abnormal returns around the announcement date $(A D)$ and the day where the new index comes into effect $(E D)$ for deletions and additions. $-1:+1$ refers to the cumulative average abnormal return and the associated tests for this period. The table also provides two tests for whether the abnormal returns are significant. The t-test is a standard t-test for whether the average is different from zero, while the sign-test is a non-parametric test for whether the number of positive returns is different from the number of negative returns. *, **, and *** denote significance at the $10 \%, 5 \%$, and $1 \%$ levels, respectively.

of the stock price effects for deletions and additions to the KFX Index.

\section{A. Stock Price Effects}

We begin by examining whether stock price effects can be found around either the announcement date or the effective date. Table 2 shows the abnormal returns for day -1 , day 0 , and day +1 relative to the announcement date and the effective date.

From table 2 it can be noted that the abnormal returns around the 
announcement date are consistently negative for deletions and positive for additions. However, the effects are generally small and insignificant in size. The only exception is for day +1 for additions, where there is a significant positive effect of $0.65 \%$. For abnormal returns around the effective date, the results are slightly more mixed. For deletions, the abnormal return on the day before the effective date is significantly negative, whereas the abnormal return on the following two days is close to zero and positive respectively, leading to an insignificant cumulative abnormal return for the period from 1 day before to 1 day after the new index comes into effect. The additions show the opposite pattern. The abnormal return on the day before the effective date is a significant $+0.97 \%$, whereas the abnormal return on the following day is significantly negative (at the $10 \%$ level according to the t-test and at the $1 \%$ level using the sign-test). The abnormal return on the day after the effective date is also negative, but not significant. All in all, this leads to an insignificant cumulative abnormal return of $+0.54 \%$ in the period from one day before to one day after the new index comes into effect. This pattern, where negative (positive) abnormal returns are followed by positive (negative) returns around the effective date, indicates the existence of price pressure. We return to this in section IV.B where the trading volume is looked at more closely.

To conclude, there is no clear overall stock price reaction for changes in the KFX Index around the announcement date, but there are indications of temporary price pressure around the effective date. However, as discussed in section II.C there are also reasons why an effect associated with a change in the index should be found in the period before the announcement. Therefore, the abnormal returns for longer time periods relative to the change in the index are examined next.

An initial look at the abnormal returns over longer periods is found in figure 1 , which plots the time pattern of cumulative average abnormal returns in the period from 120 days before to 120 days after the announcement.

Based on figure 1, it can be noted that stocks deleted from the KFX Index underperform the market by approximately $16 \%$ in the period from 120 days before to 120 days after the announcement. The under performance, which corresponds to approximately $13 \%$, is strongest in the period before the announcement, however, the effect seems to be evenly distributed in the period from 120 days before to approximately 30-40 days after the announcement.

Based on the figure, it can also be noted that stocks added to the 
TABLE 3. Cumulative Abnormal Returns for Periods Relative to the Announcement and Effective Dates

\begin{tabular}{|c|c|c|c|c|}
\hline \multicolumn{5}{|c|}{ Deletions } \\
\hline Event days & $\overline{C A R}$ & Median $C A R$ & t-test & $\%>0$ \\
\hline$A D-120: A D-26$ & $-11.27 \%$ & $-5.92 \%$ & $-2.91 * * *$ & $30.8 \% * * *$ \\
\hline$A D-25: A D-2$ & $-0.99 \%$ & $-0.96 \%$ & -0.95 & $40.4 \% *$ \\
\hline$A D-1: E D+1$ & $-3.14 \%$ & $-2.17 \%$ & $-1.79 *$ & $38.5 \% * *$ \\
\hline$E D+2: E D+120$ & $-1.35 \%$ & $-0.16 \%$ & -0.60 & $48.1 \%$ \\
\hline$A D-120: A D$ & $-12.56 \%$ & $-8.26 \%$ & $-2.97 * * *$ & $34.6 \% * * *$ \\
\hline$A D-120: E D+120$ & $-16.75 \%$ & $-11.66 \%$ & $-3.03 * * *$ & $30.8 \% * * *$ \\
\hline \multicolumn{5}{|c|}{ Additions } \\
\hline Event days & $\overline{C A R}$ & Median $C A R$ & t-test & $\%>0$ \\
\hline$A D-120: A D-26$ & $3.03 \%$ & $2.29 \%$ & 1.11 & $56.0 \%$ \\
\hline$A D-25: A D-2$ & $4.63 \%$ & $4.59 \%$ & $4.71 * * *$ & $80.0 \% * * *$ \\
\hline$A D-1: E D+1$ & $1.58 \%$ & $1.32 \%$ & 1.23 & $64.0 \% * *$ \\
\hline$E D+2: E D+120$ & $1.31 \%$ & $-0.46 \%$ & 0.81 & $48.0 \%$ \\
\hline$A D-120: A D$ & $8.21 \%$ & $5.01 \%$ & $2.76^{* * *}$ & $68.0 \% * * *$ \\
\hline$A D-120: E D+120$ & $10.56 \%$ & $9.77 \%$ & $3.19 * * *$ & $68.0 \% * * *$ \\
\hline
\end{tabular}

Note: The mean and median cumulative abnormal return $(C A R)$ and the fraction, $\%>0$, of positive cumulative abnormal returns for different time periods relative to the announcement date $(A D)$ and the effective date $(E D)$. The table also provides two tests for whether the abnormal returns are significant. The t-test is a standard t-test for whether the average is different from zero while the sign-test is a non-parametric test for whether the number of positive CAR's is different from the number of negative CAR's. *, **, and *** denote significance at the $10 \%, 5 \%$, and $1 \%$ levels, respectively.

KFX Index do relatively well compared to the market. The additions show a cumulative average abnormal return of approximately $10 \%$ in the period from 120 days before to 120 days after the announcement. ${ }^{19}$

19. Two very extreme additions were excluded when figure 1 was drawn and when studying the long-run abnormal returns in the following. The two excluded additions are Internet stocks (Navision and i-data) which had an abnormal return of 148\% and 190\%, respectively, in the 120 day period before they were added to the KFX Index. They are excluded because they would influence the abnormal return in favor of finding a positive stock price effect in the period before the addition to the KFX Index, but the following conclusions do not depend on whether these two stocks are included in the analysis or not. 


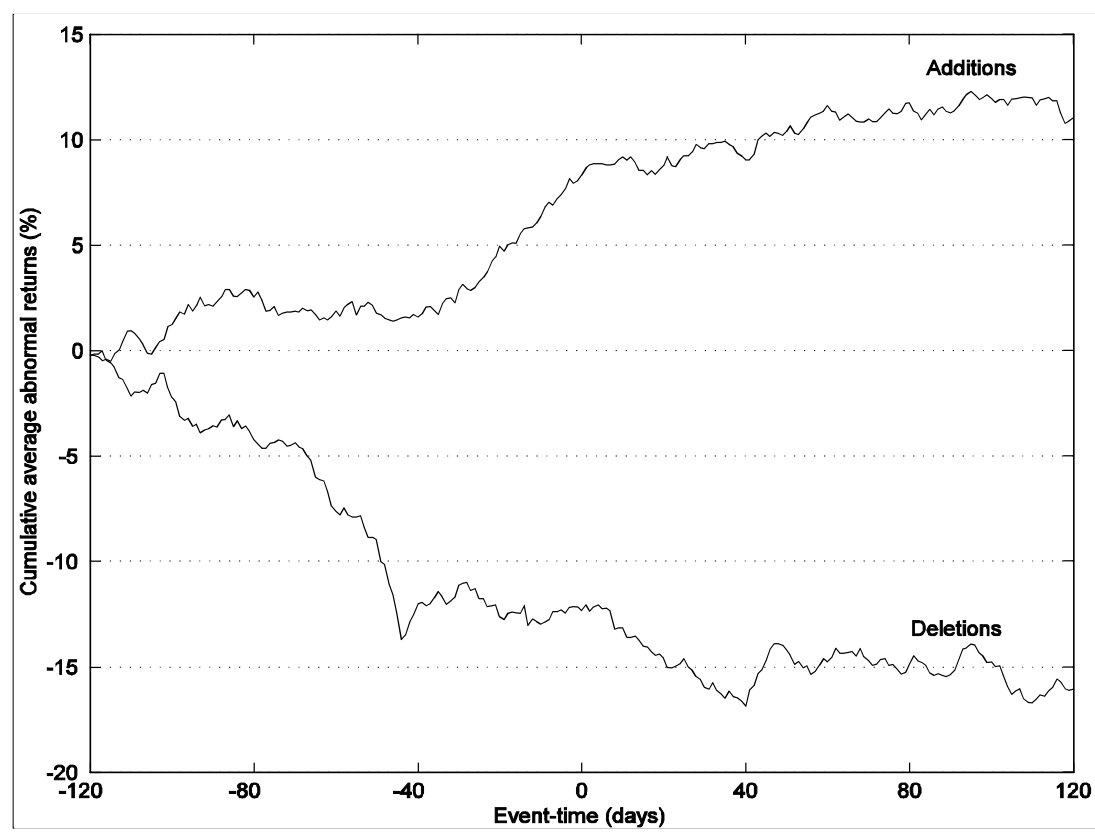

FIGURE 1.- the Time Pattern in Event-Time of the Cumulative Average Abnormal Return for Deletions and Additions to the KFX Index. Day 0 is the Announcement Date

However, it is primarily in a relatively short period leading up to the announcement that these stocks yield a higher return than the market. Thus, the figure shows that additions to the KFX Index experience a positive effect on stock prices, and that this effect results in an abnormal return of 5\%-6\% within the month just before the announcement.

The statistical analyses presented in table 3 confirm the observations made based on figure 1. For deletions in particular, the cumulative abnormal return is $-16.75 \%$ for the period from 120 days before the announcement date to 120 days after the effective date. The effect is significantly negative in several of the time periods. For additions, the cumulative average abnormal return is only significant in one of the time periods considered, namely from 25 days to 2 days before the announcement date. ${ }^{20}$ The average "effect" of being added to the KFX

20. The reason for choosing this specific time period is given in footnote 9 . 
Index in this period is a significant $4.63 \%$ (median $4.59 \%$ ). The asymmetry in the effects between additions and deletions is discussed further in the next subsection in connection with the results on trading volume. The table also provides some evidence for a stock price effect in the period from the announcement to the effective date. Similar findings have been documented for other indices; e.g., Lynch and Mendenhall (1997) for the S\&P 500. The explanation suggested is the existence of (weak) price pressure during this period as investors (or speculators/arbitrageurs) buy stocks that will be added to the index and sell stocks that will be deleted. ${ }^{21}$

For both types of revisions, we observe that the abnormal returns are insignificant in the period after the effective date. This observation is consistent with two interpretations: (i) a permanent stock price effect in the sense that there is no price reversal after the effective date and (ii) the selection bias hypothesis. Therefore, as discussed above, the KFX selection criterion makes it difficult to state the cause of the stock price effect of being deleted or added to the KFX Index and to obtain an exact estimate of the effect.

Given the difficulties in determining the cause and size of the stock price effect, it is worth noticing the following. In addition to the example from the introduction, the data-set provides other examples where, on a specific day, the stock market gets new information with regard to deletions and/or additions to the KFX Index. In general, these are situations where there is uncertainty about changes in the index until the day of the announcement due to close competition between a few stocks; e.g., footnote 1 . The evidence found in these cases is consistent with the above findings and suggests a stock price effect in the order of $5 \%$ to $10 \%$. Interestingly, the same also applies for the few recent changes determined by using the new selection criterion, according to which a selection bias effect should be less pronounced. ${ }^{22}$

21. This is related to what is known as the "S\&P Game" where arbitrageurs buy stocks added to the index following the announcement and then later, when the new index comes into effect, sell the stocks to index trackers and others who want to hold index stocks. See Beneish and Whaley (1996) and Lynch and Mendenhall (1997).

22. For example, for the three most recent additions seen in table 1 , the average cumulative abnormal return over the period $A D-120$ : $A D-40$ is $1.97 \%$, while it is $8.84 \%$ over the period $A D-39: A D-2$, and these results are not caused by a single outlier. Furthermore, the results suggest that the effect for these additions starts earlier than the 26 day period considered in table 3. This is perfectly consistent with a much simpler selection criterion and the fact that the Copenhagen Stock Exchange, on November 12, 2001, started publishing estimates of the 
Additional evidence against the selection bias hypothesis as the single explanation for the stock market effects can be found by examining the group of deletions more closely. For the 26 deletions that occurred from 1993 and until June 2001, information is available that makes it possible to determine if a deletion is caused by a drop in market value or by a drop in trading volume. For these 26 deletions, 16 deletions are due to a decrease in market value and 10 deletions are due to a drop trading volume, again indicating that a decrease in market value is the most common reason for a deletion. ${ }^{23}$ Furthermore, from unreported results follow that the average (median) stock price effect in the period $A D-120: A D$ is $-29.82 \%(-22.77 \%)$ for the group where the deletion is caused by a drop in market value. For the other group, the average (median) stock price effect is $-8.34 \%(-11.68 \%)$, and the two groups are significantly different at the $5 \%$ level using a standard t-test for the difference in the means. Hence, there is a fairly large negative stock price effect even for the group where the deletion is caused by a drop in trading volume. Therefore, these results provide additional strong evidence that the stock market effect is not caused by a selection bias alone.

When the cross-sectional relation of the stock price effects is examined in section IV.C, we will consider the stock return over the period from 120 days before the announcement to the announcement, i.e. the effect over $A D-120: A D$ as also reported in table 3.

Having examined the stock price effects for changes in the index, the next step is to examine the stock returns by running the market model regression in equation (1). The results from this regression can be found in table 4.

Based on the table, deletions have a significant decrease in the $\beta$-value, while additions have a significant increase. The table also shows that deletions have a significant increase in the $\beta_{-1}$-value such that the $\beta_{-1}$-parameter is highly significant after the stock is deleted from

composition of the KFX Index on a daily basis during the whole reference period.

23. From 1993 and onwards, the stock exchange has published the basis portfolio, which is described together with the selection procedure for the KFX Index in section II. Therefore, if a deleted stock is still found in the basis portfolio the deletion must be due to a drop in market value relative to other stocks. However, if the stock is no longer in the basis portfolio, the deletion must primarily be due to a drop in liquidity. Here it is worth to stress that for 8 out of the 10 stocks, the deletion is entirely due to a drop in trading volume because the market volume is higher than what is needed in order to be included in the index at that time. The conclusions regarding the stock market effect is unchanged if only these 8 stocks are considered. 
TABLE 4. Estimated Market Model Parameters for Regression (1)

\begin{tabular}{|c|c|c|c|c|}
\hline \multicolumn{5}{|c|}{ Deletions } \\
\hline Time period & $\beta$ & $\beta_{-1}$ & sum- $\beta$ & $\operatorname{var}(\mathcal{E})$ \\
\hline \multicolumn{5}{|l|}{ Before announcement } \\
\hline Mean & 0.958 & -0.039 & 0.919 & 2.741 \\
\hline Median & 0.899 & -0.047 & 0.898 & 1.755 \\
\hline \multicolumn{5}{|l|}{ After change in index } \\
\hline Mean & $0.731 * * *$ & $0.142 * * *$ & $0.874 *$ & 3.061 \\
\hline Median & 0.715 & 0.152 & 0.823 & 1.923 \\
\hline \multicolumn{5}{|l|}{ Difference after-before } \\
\hline Mean & $-0.227 * *$ & $0.181 * *$ & -0.046 & 0.320 \\
\hline Median & -0.207 & 0.121 & -0.078 & 0.200 \\
\hline$\%$ with an increase & $25.0 \% * * *$ & $71.2 \% * * *$ & $38.5 \% * *$ & $59.6 \% *$ \\
\hline \multicolumn{5}{|c|}{ Additions } \\
\hline Time period & $\beta$ & $\beta_{-1}$ & sum- $\beta$ & $\operatorname{var}(\mathcal{E})$ \\
\hline \multicolumn{5}{|l|}{ Before announcement } \\
\hline Mean & $0.728 * * *$ & $0.067 * *$ & $0.795 * * *$ & 2.559 \\
\hline Median & 0.651 & 0.042 & 0.705 & 1.527 \\
\hline \multicolumn{5}{|l|}{ After change in index } \\
\hline Mean & 0.972 & 0.030 & 1.002 & 2.429 \\
\hline Median & 0.962 & 0.012 & 0.992 & 1.512 \\
\hline \multicolumn{5}{|l|}{ Difference after-before } \\
\hline Mean & $0.243 * *$ & -0.037 & $0.206 * * *$ & -0.130 \\
\hline Median & 0.165 & -0.027 & 0.251 & -0.234 \\
\hline$\%$ with an increase & $63.5 \% * *$ & $46.1 \%$ & $65.4 \% * *$ & $46.2 \%$ \\
\hline
\end{tabular}

Note: Estimated market model parameters for deletions and additions to the KFX Index for the ordinary least squares regression described in equation (1). The sum- $\beta$ is calculated as the sum of $\beta$ and $\beta_{-1}$. $\operatorname{Var}(\varepsilon)$ is the variance of the residual term in the regression. 'Before announcement' is from $A D-150$ to $A D+30$, while 'After change in index' is from $E D+30$ to $E D+150$. For $\beta_{-1}$ the test is for the significance of the estimated parameters, whereas for $\beta$ and sum- $\beta$, the test is for the difference from 1 . All of these are based on a standard t-test. 'Difference after-before' denotes the difference between the parameters from the two periods described above. The tests for the difference in parameters between these two periods are standard t-tests for the difference of means between two samples. For ' $\%$ with an increase' the sign-test is used to test if the number of increases is different from the number of decreases. ${ }^{*}, * *$, and $* * *$ denote significance at the $10 \%, 5 \%$, and $1 \%$ levels, respectively.

the index. This means that the stock returns of deleted stocks are less synchronous after the deletion, and hence inefficiency has increased. Additions experience the opposite, i.e. $\beta_{-1}$ decrease even though the change is not significant at the $10 \%$ level. Hence, with respect to efficiency, there is asymmetry between the effects for the two types of 
revisions. This asymmetry is consistent with the findings on trading volume and is therefore discussed along with the results for trading volume in the next subsection.

Table 4 also provides results on the sum of the two $\beta$-values, the so-called sum- $\beta$, which is a modified version of Scholes and William's (1977) $\beta$-value. ${ }^{24}$ For additions, a large and significant increase in the sum- $\beta$ is observed. For deletions, the sum- $\beta$ decreases, but the change is small and only significant based on the test for the fraction with a decrease. All these findings are interesting in relation to the findings of Vijh (1994) and Chung and Kryzanowski (1998). In particular Vijh (1994), who documents that betas increase for stocks added to the S\&P 500 , explains that the increase is due to a reduction in the nonsynchroneity of stock prices as well as the excess volatility caused by index trading strategies. Chung and Kryzanowski (1998) find that betas increase (decrease) for additions to (deletions from) the Canadian TSE300, but none of the changes are significant. Furthermore, Chung and Kryzanowski (1998) do not provide any results of the effect on the $\beta_{-1}$-value.

Finally, the table does not provide any evidence that a change in the KFX Index leads to a significant change in the variance of the residual from the market model, suggesting that a deletion or addition to the KFX Index does not change the precision with which firm-specific information is incorporated in stock prices.

\section{B. Trading Volume Effects}

As for the stock price effect, the trading volume close to the announcement date and the effective date are described briefly by considering the simple turnover in the days surrounding the two dates. ${ }^{25}$ Based on unreported results, no evidence was found that the time pattern in turnover around the announcement date is related to the announcement itself. However, for the effective date, there is a highly significant peak in turnover on the day prior to the effective date. For example, the average (median) turnover on the day before the effective day is $0.27 \%$

24. This sum- $\beta$ is the $\beta$-value used by Ibbotson Associates. For a further discussion of the sum- $\beta$ see, for example, Campbell and Vuolteenaho (2003).

25. Turnover is defined as the number of shares traded divided by the total number of shares outstanding in the firm. Similar results are obtained using other measures of trading volume. All the results described in this paper are available upon request. 
$(0.14 \%)$ for additions compared to an average (median) of $0.16 \%$ $(0.07 \%)$ for the period from -5 to 5 days relative to the effective date (excluding day -1 ). For deletions, the average (median) on day -1 is $0.41 \%(0.16 \%)$ compared to $0.15 \%(0.04 \%)$ for the days around the effective date. Furthermore, there is also some evidence of high turnover for deletions on the effective date with a mean turnover of $0.30 \%$.

Such abnormal turnover on the day before (and partly also on) the effective date indicates that some investors adjust their portfolios in accordance with the change in the KFX Index. However, the increase in turnover on the day prior to the effective date appears to be most pronounced for deletions. This indicates that investors find it more important to make necessary adjustments of their portfolios for deletions than for additions before the change in the index comes into effect. For example, investors who are required to hold only KFX stocks have to sell before a deletion from the index becomes effective. For stocks added to the index, there is perhaps more flexibility regarding when the stocks are purchased. All in all, these findings on trading volume are perfectly consistent with the results in table 2 . Hence, as discussed in section IV.A, the trading volume provides additional evidence for a temporary price pressure around the effective day. Similar evidence for price pressure with regard to index revisions is found in a number of studies. The size and location of the price pressure found here are consistent with; e.g., Lynch and Mendenhall (1997), Chung and Kryzanowski (1998), and Elliott and Warr (2003).

The long-run effects on trading volume for deletions and additions to the KFX Index are found in table 5 for the measure defined in equation (2). The results in this table show a significant decrease in the trading volume for deletions while additions only experience a small and insignificant increase in trading volume. The fact that there is no clear increase in trading volume for additions can perhaps be explained by two factors. First, consistent with the selection criterion, the additions are clearly more heavily traded than deletions in the period before the revision. Hence, being added to the KFX Index may help the stocks maintain this high level of trading volume. ${ }^{26}$ The other factor is related

26. Anecdotal evidence also suggests that stocks in the KFX Index are generally more heavily traded than stocks outside the index. The three columns to the right in table 1 shows the number of changes in the KFX Index since the new selection criterion considering only trading volume became effective. Based on this, there has been only one regular change in the KFX Index during this period (the two additions in 2002 happened due to the delisting of two KFX stocks), suggesting that the new selection criterion has increased the likelihood of 
TABLE 5. Relative Trading Volume for Deletions from and Additions to the KFX Index

\begin{tabular}{lcccc}
\hline \multirow{2}{*}{ Time period } & \multicolumn{2}{c}{ Deletions } & \multicolumn{2}{c}{ Additions } \\
& mean(\%) & median $(\%)$ & mean $(\%)$ & median $(\%)$ \\
\hline (a) $A D-120: A D-26$ & 0.718 & 0.602 & 1.103 & 0.826 \\
(b) $A D-25: E D+5$ & 0.626 & 0.543 & 1.118 & 0.916 \\
(c) $E D+6: E D+120$ & 0.569 & 0.527 & 1.250 & 0.836 \\
& & & & \\
Diff. (c) minus (a) & $-0.150 * *$ & -0.099 & 0.147 & 0.049 \\
$\%$ with an increase & $30 \% * * *$ & & $52 \%$ & \\
\hline
\end{tabular}

Note: Relative volume defined in equation (2) for deletions and additions to the KFX Index for three different periods relative to the announcement date $(A D)$ and the effective date $(E D)$. 'Diff. (c) minus (a)' denotes the difference between the volume ratios from period (c) and period (a). The test for a difference in trading volume between these two periods is a standard t-test for the difference of means between two samples and a binomial test for whether the number of increases is different from the number of decreases. *, **, and *** denote significance at the $10 \%, 5 \%$, and $1 \%$ levels, respectively.

to the group of investors who mainly buy stocks in the index. If they primarily follow a buy-and-hold strategy, the stocks added to the index are not expected to experience a significant increase in trading volume.

These long-run effects on trading volume are consistent with the results on trading volume found for some other indices. ${ }^{27}$ Furthermore, the effects found here are consistent with the changes in efficiency considered in table 4. In particular, deletions experience a significant decrease in trading volume and efficiency, while the effects for additions are insignificant. Similarly, section IV.A shows that the stock price effect seems to be larger for deletions than for additions. These asymmetries are all consistent with the discussions found in section II.C, suggesting that the effects of being deleted from the KFX Index might be more severe than the effects of being added. Similar findings and arguments are found in Beneish and Gardner (1995).

current KFX stocks continuing as KFX stocks.

27. Long-run effects on trading volume are found in, for example, Harris and Gurel (1986), Beneish and Gardner (1995), Beneish and Whaley (1996), Liu (2000), and Chan and Howard (2002). Chung and Kryzanowski (1998) do not find any long-run effects on trading volume, which may be the reason why they do not find any permanent effect on stock prices. 


\section{Cross-sectional Analysis of the Abnormal Returns}

The above provides evidence for a small temporary price pressure effect close to the effective date and a larger stock price effect of a more permanent nature observed in the period before the announcement date. The permanent stock price effect can be explained by several competing explanations, including the selection bias hypothesis as discussed in section II.C. This section examines the relationship between the stock price effects and seven factors which are possibly relevant in explaining these effects.

The first factor is a measure of the change in the amount of attention paid to a firm, which is relevant if the stock price effect is explained by the information costs/liquidity hypothesis. To be more exact, we calculate an attention index, $A I$, defined as the number of times the firm is mentioned in the primary Danish financial newspaper, Børsen, for a 140 day period after the change in the index, divided by the same number for a 140 day period before the announcement of the change. ${ }^{28}$ This attention index is quite similar to the information variable, which, as shown by Beneish and Gardner (1995), is documented as having a positive and significant effect on the stock price reaction to changes in the Dow Jones Industrial Average.

The second factor is the index weight, $I W$, defined as the weight the stock either had in the index before deletion or is going to have in the index after addition. The index weight is a measure of the change in demand for the stock by, for example, index trackers, and hence, is relevant if the imperfect substitutes hypothesis applies. The importance of the index weight is documented, among others, by Kaul, Mehrotra, and Morck (2000). Furthermore, the index weight is also a measure of the size of the firm, which has been examined in, for example, Jain (1987), Edmister, Graham, and Pirie (1994), Chung and Kryzanowski (1998), and Madhavan (2002). However, only Madhavan (2002) finds evidence for a significant relation between the stock price effect and the size of the firm.

The third and fourth factors measure changes in the $\beta$-factors, $\Delta \beta$ and $\Delta \beta_{-1}$, where $\beta$ and $\beta_{-1}$ are from regression (1) and table 4 . These changes are relevant according to the information costs/liquidity hypothesis but have not been examined in a cross-sectional regression

28. More precisely, in order to avoid the announcement of the index revision influencing the measure, the two periods are defined as $E D+10: E D+150$ and $A D-180: A D-40$. 
before. However, Madhavan (2002) includes a simple beta in his regression, but the factor is insignificant.

Similarly, the fifth factor, $\Delta V R$ is the change in trading volume measured by $V R$, defined in (2) and as considered in table 5. Thereby, this factor is related to the imperfect substitutes hypothesis and the information costs/liquidity hypothesis. This approach shares similarities with that taken by studies such as Chung and Kryzanowski (1998) and Madhavan (2002). In particular, Chung and Kryzanowski (1998) examine changes in other volume related factors but do not find any evidence for a significant relation between these and the announcement window abnormal returns.

The two remaining factors are included in order to examine some potentially interesting aspects of the stock price effects. As mentioned, a quite unique feature of the KFX Index is that stocks can be deleted or added to the index several times. In order to examine if the effects depend on whether or not it is the first time a stock experiences a deletion or an addition, the sixth factor, $S T$, is included in the regression. $S T$ is a dummy which is zero if it is the first time the stock experiences the change under consideration (being deleted or added) and 1 otherwise. The seventh factor $Y$, which examines whether the effects increase over time, is a trend variable which is 0 for changes in 1989, 1 for changes in 1990, 2 for changes in 1991 and so on. A number of papers have documented an increase in the stock price effect over time; e.g., Shleifer (1986), Dhillon and Johnson (1991), Deininger, Kaserer, and Roos (2002), and Chen, Noronha, and Singal (2004).

Given these factors and $C A R$, defined as the cumulative abnormal stock return for the period $A D-120$ to $A D$, the following cross sectional regression is run:

$$
\begin{aligned}
C A R_{i}= & \gamma_{0}+\gamma_{1} A I_{i}+\gamma_{2} I W_{i}+\gamma_{3} \Delta \beta_{i}+\gamma_{4} \Delta \beta_{-1, i} \\
& +\gamma_{5} \Delta V R_{i}+\gamma_{6} S T_{i}+\gamma_{7} Y_{i}+\varepsilon_{i}
\end{aligned}
$$

Table 6 provides results from the regression in equation (3). The two joint regressions show that only two variables are significant for deletions and no variables are significant for additions. One explanation for this is multicollinearity in the regression. Several of the variables, including, for example, the attention index, the trend variable, and the change in trading volume turn out to be correlated. These correlations 


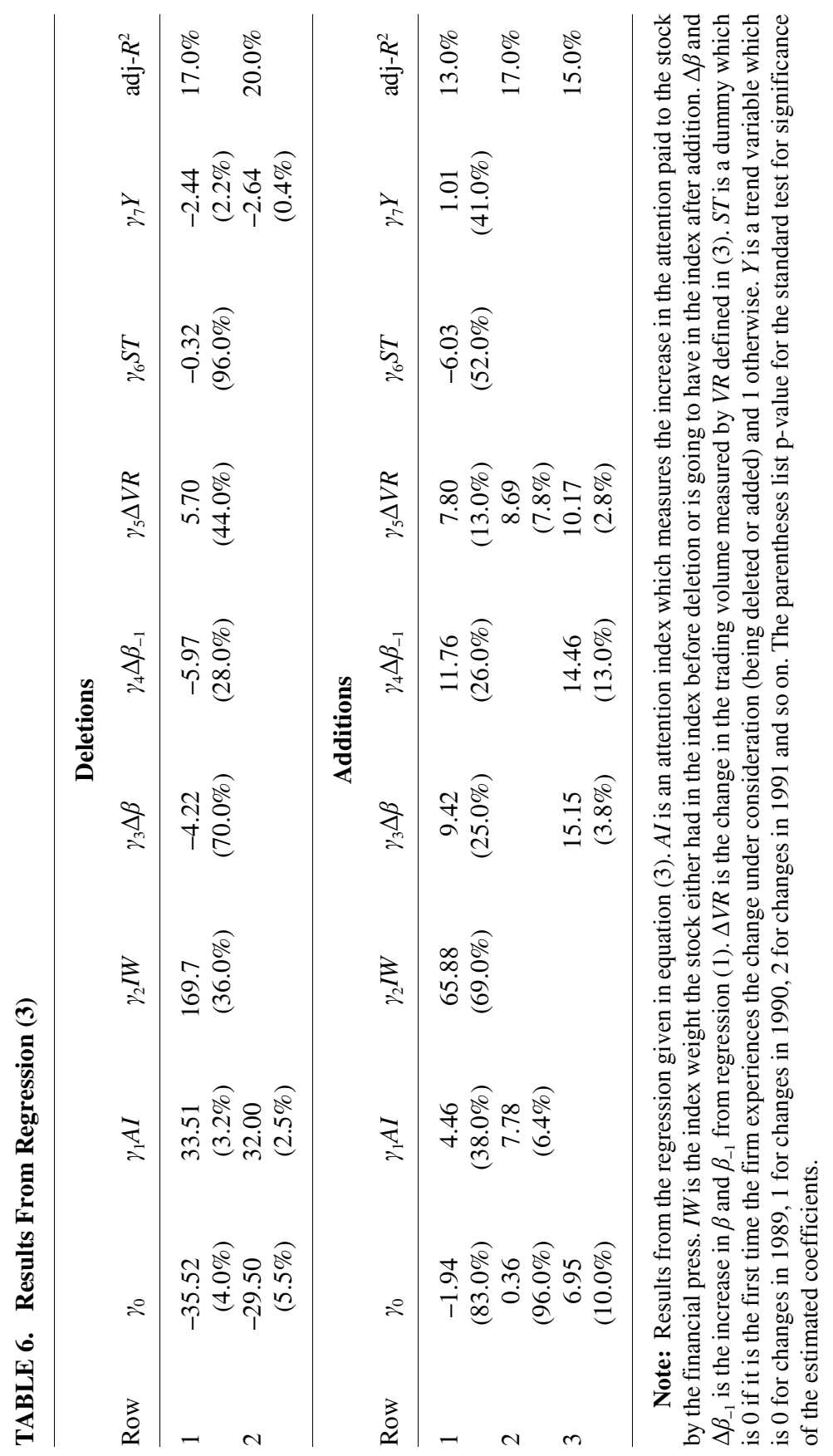


are consistent with an increase over time in the attention paid to the index, and hence also an increase in the implications for trading volume. Therefore, the table also presents results for other regressions where different insignificant variables have been excluded from the regression. These results are discussed in detail in the following.

First, there is a positive relation between the attention index, $A I$, and the stock price effect for deletions as well as for additions. For deletions, the relation is generally significant at the 5\% level, while the level of significance varies for additions. However, unreported results show that the attention index is significant at the $1 \%$ level in a univariate regression. For revisions in the KFX Index, this means that a higher increase (decrease) in the attention paid to a stock leads to a more positive (negative) stock price effect. Furthermore, the attention index itself also shows that deletions experience a decrease and additions an increase in the attention paid to them by the financial press. For deletions, the average attention index is 0.95 (median 0.94), while the average for additions is 2.11 (median 1.66). These results suggest the importance of attention/awareness with regard to index revisions as also discussed in Chen, Noronha, and Singal (2004).

Second, the trend variable, $Y$, is significantly negative for deletions and positive (at the $7 \%$ level in a univariate regression) for additions, which means that the absolute value of the stock price effect has increased over time. According to the arguments in section II, this is consistent with the increased focus on the KFX Index caused by an increase in investment funds, benchmarking, and foreign investors over time. ${ }^{29}$ As discussed in section II.C, such an increase over time can also be argued to indicate that the selection bias explanation is not the only reason for the stock price effects occurring around changes in the KFX Index. Third, for deletions, none of the other variables are significant in joint or univariate regressions. This means that the index weight, $I W$, the changes in the two different $\beta s\left(\Delta \beta\right.$ and $\left.\Delta \beta_{-1}\right)$, and the change in trading volume, $\Delta V R$, do not seem to be relevant in explaining the stock price

29. In order to investigate this even further, the stock price effects are considered using other time periods than those used above. If, for deletions, the period $A D-120: E D+120$ is considered, as in table 3, we find that the median stock price effect before 1994 is $-13.52 \%$, while it is $-22.97 \%$ after 1994 . If, for additions, the last month before the announcement of the change is considered, then the median before 1994 is $2.84 \%$, while it is $6.55 \%$ after 1994 . The year 1994 was used to divide the sample into two groups because, as mentioned in footnote 9, it was the year the Danish financial press started announcing predictions on changes in the KFX Index. The conclusions are the same if the data set is instead divided into two groups of equal size. 
effect. For additions, there is some evidence for a positive relationship between the stock price effect and the change in the $\beta$-value as well as the change in trading volume. The change in trading volume especially seems to be relevant in explaining the cross sectional variation in the stock price effect. The change in trading volume is significant at the $2 \%$ level in a univariate regression whereas the change in the $\beta$-value is significant at the $10 \%$ level.

There is no obvious reason why more factors seem to be important in explaining the stock price effect for additions than for deletions. However, as mentioned, one possible explanation is that the selection bias problem may be more pronounced for deletions than for additions. One main reason for this is as follows. The results in section IV.B suggest that membership in the KFX Index implies a high level of trading volume. Therefore, given the two dimensional selection criterion, decreasing market value will often be the reason for deletions from the index (see also section II.C and footnote 26), which especially for deletions may make it difficult to measure the exact stock price effect associated with being part of the KFX Index. This observation is also consistent with the pattern in figure 1, where the stock price effect for deletions is distributed over a longer period before the announcement.

Finally, it should be noted that the dummy variable $S T$ is insignificant for deletions and additions, which implies that the stock market effect does not depend on whether or not it is the first time that a stock is being deleted or added to the index. ${ }^{30}$ This is interesting because the selection criterion for the KFX Index is unique compared to, for example, the S\&P 500 in the sense that it is possible for a stock to be deleted and added to the KFX Index several times. These results suggest that it is special for a stock to be a member of the KFX Index and that this 'something special' is lost in the case of deletions. Thus, the explanation does not seem to be investor awareness as suggested by

30. There are 35 stocks that have been deleted from the KFX Index for the first time, while there are 17 that have been deleted from the KFX Index before. The median stock price effect in the same period as considered above is $-14.11 \%$ for the first group and it is $-17.63 \%$ for the second group. Furthermore, a t-test and other tests provide no evidence for a difference between the two groups. Similarly, there are 37 stocks that have been added to the KFX Index for the first time, while there are 15 that have been added to the index before. Using the same time period as above, the median stock price effect for the first group is $3.79 \%$ and $6.48 \%$ for the second group. Moreover, there is no evidence for a difference between the two groups based on a t-test and other tests. The indications of a greater effect for stocks that have already experienced a similar change in the KFX Index are explained by the findings of an increase in the effect over time. 
Chen, Noronha, and Singal (2004) in the case of the S\&P 500.

To conclude, the cross-sectional analysis of stock price effects shows that the attention paid to stocks in the KFX Index is important in explaining stock price effects. In addition, the results on the change in $\beta$ and trading volume for additions indicate the importance of these efficiency and liquidity related factors. Therefore, the results suggest that the imperfect substitutes and information cost/liquidity hypotheses are the explanations for why it is special to be in the KFX Index. However, the results also suggest that the selection bias, at least for deletions, may be relevant in explaining part of the stock price effect.

\section{Summary and Conclusions}

This paper has provided evidence that deletions from the KFX Index experience an average abnormal return of $-13 \%$, while the average abnormal return is $8 \%$ for additions. The stock price effect is permanent and consistent with the publicly announced selection criterion, primarily observed in the period before the change. The size of the effect has increased over time and there is an effect every time a stock is deleted or added to the index. In addition, results on stock returns and trading volume indicate the existence of temporary price pressure around the effective date. Efficiency and trading volume decrease significantly for deletions, while additions only experience an insignificant increase in efficiency and trading volume. This weak increase in trading volume for additions can at least, in part, be explained by two factors. First, the trading volume is much higher for additions than for deletions in the period before the change. Second, investors buying the stocks added to the index may simply hold on to the stock as long as the stock is part of the index. These asymmetries in the effect on efficiency and trading volume also help to explain the asymmetry in the size of the stock price effect between deletions and additions.

The permanent nature of the stock price effect, the change in efficiency, the evidence on trading volume, and the cross-sectional analysis of stock price effects suggest that the imperfect substitutes and information cost/liquidity hypotheses are the most likely explanations for the effects on stock prices and trading volume. However, the evidence does not rule out the selection bias as an explanation for part of the stock price effects.

Given these results, it is difficult to say whether the recent change 
in the selection criterion will change the effects of being deleted or added to the KFX Index. However, when total market value is no longer part of the selection criterion, the evidence suggests that once included in the KFX Index, it is quite likely that the stock will be able to maintain membership in the index, which could increase the effect. Furthermore, it is reasonable to believe that the new selection criterion will make it more likely that relatively small firms will be added to the index. For these smaller firms, the information cost/liquidity hypothesis predicts a larger stock price effect.

The results for the KFX Index have at least two important contributions to make to the existing literature on index revisions. First, there is evidence of several asymmetries between deletions and additions to the KFX Index, and these asymmetries are different from the most recent findings for the S\&P 500 index. In particular, and in contrast to Chen, Noronha, and Singal (2004), the evidence from the KFX Index suggests that the causes of the stock market effects are related to membership in the index rather than to the investor awareness caused by being included in the index. Thereby, the results also confirm the importance of studying both deletions from and additions to an index in order to identify such asymmetries in the stock market effects.

The second contribution concerns the importance of the selection criterion used for an index and the relevance of the size of the index and the related stock market. As suggested by results in this paper, the selection bias hypothesis can be relevant when interpreting the effects of index revision. Hence, studies of index revisions should ideally also include a description of the selection criterion used for the index as well as a discussion of its implications for the results. This especially concerns indices where the market value of stock is part of the selection criterion. Similarly, the size of an index and the related stock market are of relevance when explaining the stock market effects of index revisions. This particularly applies when a possible explanation is the imperfect substitutes hypothesis or is related to investor awareness.

\section{References}

Amihud, Y.; Mendelson, H.; and Lauterbach, B. 1997. Market microstructure and securities values: Evidence from the Tel Aviv Stock Exchange. Journal of Financial Economics 45:365-390.

Barontini, R. and Rigamonti, S. 2000. Stock index futures and the effect on the cash market in Italy: Evidence from changes in indexes' composition. 
Working paper. Università Cattolica del S. Cuore.

Beneish, M. D. and Gardner, J. C. 1995. Information costs and liquidity effects from changes in the Dow Jones Industrial Average List. Journal of Financial and Quantitative Analysis 30(1):135-157.

Beneish, M. D. and Whaley, R. E. 1996. An anatomy of the 'S\&P Game': The effects of changing the rules. Journal of Finance 51(5):1909-1930.

Bildik, R. and Gulay, G. 2001. Effects of changes in index composition on stock market: Evidence from the Istanbul Stock Exchange. Working paper. Istanbul Stock Exchange.

Brealey, R. A. 2000. Stock prices, stock indexes and index funds. Bank of England Quarterly Bulletin 40(1):61-68.

Campbell, J. Y.; Lo, A. W.; and MacKinlay, A. C. 1997. The Econometrics of Financial Markets. New Jersey: Princeton University Press.

Campbell, J. Y. and Vuolteenaho, T. 2003. Bad beta, good beta. Working paper. Harvard University.

Chan, H. W. and Howard, P. F. 2002. Additions to and deletions from an open-ended market index: Evidence from the Australian All Ordinaries. Australian Journal of Management 27(1):45-74.

Chen, H.; Noronha, G.; and Singal, V. 2004. Price response to S\&P 500 Index additions and deletions: Evidence of asymmetry and a new explanation. Journal of Finance, forthcoming.

Chung, R. and Kryzanowski, L. 1998. Are the market effects associated with revisions to the TSE300 Index robust? Multinational Finance Journal 2(1):1-36.

Deininger, C.; Kaserer, C.; and Roos, S. 2002. Der Indexeffekt am deutschen Aktienmarkt und seine Ursachen. Zeitschrift für Bankrecht und Bankwirtschaft 4:262-279.

Dhillon, U. and Johnson, H. 1991. Changes in the Standard and Poor's 500 List. Journal of Business 64(1):75-85.

Edmister, R. O.; Graham, A. S.; and Pirie, W. L. 1994. Excess returns of index replacement stocks: Evidence of liquidity and substitutability. Journal of Financial Research 17(3):333-346.

Elayan, F.; Li, W.; and Pinfold, J. 2001. Price effects of changes to the composition of New Zealand Share Indices. The New Zealand Investment Analyst 21:25-30.

Elliott, W. and Warr, R. 2003. Price pressure on the NYSE and Nasdaq: Evidence from S\&P 500 Index changes. Financial Management Autumn:85-99.

Fama, E. F. 1998. Market efficiency, long-term returns, and behavioral finance. Journal of Financial Economics 49:283-306.

Harris, L. and Gurel, E. 1986. Price and volume effects associated with changes in the S\&P 500 List: New evidence for the existence of price pressures. Journal of Finance 41(4):815-829.

Hegde, S. P. and McDermott, J. B. 2003. The liquidity effects of revisions to 
the S\&P 500 Index: An empirical analysis. Journal of Financial Markets 6(3):413-459.

Jain, P. C. 1987. The effect on stock price of inclusion in or exclusion from the S\&P 500. Financial Analysts Journal 43(January/February):58-65.

Jiang, L. and Kryzanowski, L. 1997. Trading activity, quoted liquidity, and stock volatility. Multinational Finance Journal 1(3):199-227.

Kaul, A.; Mehrotra, V.; and Morck, R. 2000. Demand curves for stocks do slope down: New evidence from an index weights adjustment. Journal of Finance 55(2):893-912.

Liu, S. 2000. Changes in the Nikkei 500: New evidence for downward sloping demand curves for stocks. International Review of Finance 1(4):245-267.

Lynch, A. W. and Mendenhall, R. R. 1997. New evidence on stock price effects associated with changes in the S\&P 500 Index. Journal of Business 70(3):351-383.

Lyon, J. D.; Barber, B. M.; and Tsai, C.-L. 1999. Improved methods for tests of long-run abnormal stock returns. Journal of Finance 54(1):165-201.

Madhavan, A. 2002. Index reconstitution and equity returns. Working paper. ITG Inc.

Pruitt, S. W. and Wei, K. C. J. 1989. Institutional ownership and changes in the S\&P 500. Journal of Finance 44(2):509-513.

Scholes, M. and Williams, J. 1977. Estimating beta from nonsynchronous data. Journal of Financial Economics 5(3):309-327.

Shleifer, A. 1986. Do demand curves for stocks slope down? Journal of Finance 41(3):579-590.

Travlos, N.; Trigeorgis, L.; and Vafeas, N. 2001. Shareholder wealth effects of dividend policy changes in an emerging stock market: The case of Cyprus. Multinational Finance Journal 5(2):87-112.

Vijh, A. M. 1994. S\&P 500 trading strategies and stock betas. Review of Financial Studies 7:215-251.

Wurgler, J. and Zhuravskaya, K. 2002. Does arbitrage flatten demand curves for stocks? Journal of Business 75(4):583-608. 